\title{
Transcatheter aortic valve replacement and surgical aortic valve replacement volume-outcome relationships: a Pandora's box
}

\author{
Sreekanth Vemulapalli ${ }^{1,2,3}$ \\ ${ }^{1}$ Duke Clinical Research Institute, ${ }^{2}$ Duke-Margolis Center for Health Policy, ${ }^{3}$ Division of Cardiology, Duke University Medical Center, Durham, \\ NC, USA \\ Correspondence to: Sreekanth Vemulapalli. Box 3026, 2301 Erwin Rd, Duke University Medical Center, Durham, NC 27710, USA. \\ Email: Sreekanth.vemulapalli@duke.edu.
}

Submitted Feb 26, 2020. Accepted for publication Apr 15, 2020.

doi: 10.21037/acs-2020-av-16

View this article at: http://dx.doi.org/10.21037/acs-2020-av-16

'Pandora's box'-a 'source of great and unexpected troubles' or 'a present which seems valuable, but which in reality is a curse'.

The introduction of transcatheter aortic valve replacement (TAVR) heralded a sea-change in the treatment of aortic stenosis (AS) and has been recognized as one of the five most important advancements in cardiovascular disease over the last 20 years. Given the dearth of prospective data for valvular heart disease (VHD) (1), clinical trials supporting the efficacy of TAVR have transformed the evidence base in VHD. However, history has shown that the translation of therapies supported by clinical trial data to everyday practice is rife with pitfalls, including variable quality.

The framework for healthcare quality metrics was established by Donabedian over 50 years ago. Quality measures fall into one of three categories: (I) structural; (II) process; (III) outcomes. Structural measures, such as procedural volumes, have the benefit of being easily measured; however, they are essentially surrogates for risk-adjusted outcomes measures. Surgery and cardiology have a rich history of demonstrating volume-outcome relationships $(2,3)$. On the strength of that history in other procedures, the Centers for Medicare and Medicaid Services (CMS) issued a national coverage decision (NCD) in 2012 that required the performance of $\geq 20$ surgical aortic valve replacements (SAVR) and $\geq 300$ percutaneous coronary interventions (PCI) to start a TAVR program $(2,3)$. Additionally, the CMS NCD required $\geq 50$ aortic valve replacements (AVRs) per year including $\geq 20$ TAVRs per year be performed per year for a program to be able to maintain its status as a TAVR center status and maintain eligibility for reimbursement in the eyes of CMS (4).

Though the volume-outcome relationship in TAVR or SAVR had yet to be proven by the time of the original CMS NCD, the NCD turned the existence of a TAVR volume-outcome relationship into a de facto quality metric and healthcare policy. While subsequent analyses have confirmed the existence of a contemporary volume-outcome relationship in TAVR (5) and SAVR (6), a focus on volume as a structural quality measure misses the opportunity to define outcome quality metrics, even after taking into account the learning curve.

The Society of Thoracic Surgeons (STS) has developed National Quality Forum (NQF)-endorsed measures for 30-day mortality and 30-day composite outcome after SAVR. Additionally, the Transcatheter Valve Therapies (TVT) Registry has developed a NQF-endorsed 30-day mortality metric (7). However, given the relatively low 30-day mortality associated with both SAVR and TAVR and the expansion of TAVR to low-risk populations, there is widespread recognition that mortality is not the only endpoint of interest for quality measurement. As a result, a 30-day post-TAVR composite metric composed of mortality, stroke, valve academic research consortium, major or disabling bleeding, stage 3 acute kidney injury and moderate/severe paravalvular leak has been derived and validated. These metrics collectively help focus the assessment of quality on the measurement of risk-adjusted outcomes rather than structural measures, such as volume. However, with the expansion of TAVR to all STS risk groups, further efforts are needed to develop AVR metrics that are agnostic of a surgical versus a percutaneous approach. 
In addition to diverting attention from the development of outcome-based quality metrics, the recent focus on the TAVR and SAVR volume-outcome relationship has overshadowed the need for research to define equitable dispersion of and access to comprehensive AVR services (8). Invariably, the use of any absolute minimum quality threshold to determine eligibility for certification of AVR programs or payment for AVR procedures will have a theoretical impact on access to AVR care (9). Yet, despite having the most TAVR centers per capita in the world, little is known about access to AVR services in the United States and the presence of disparities in access. Indeed, existing volume-outcomes and population-based analyses of patients undergoing TAVR suggest that there may be both geographic and racial/ethnic disparities in access to TAVR. However, none of these existing studies are definitive due to the lack of a nationwide data source of patients with severe and symptomatic AS. As a transformational technology, TAVR is at risk of perpetuating existing disparities in the United States healthcare system. This is because innovative technologies often initially favor patients with the most resources, influence, social connections and insurance coverage. Further complicating the issue of defining disparities in AVR is that access to care itself is a complex construct involving geography, socioeconomic status, ethnicity, race, insurance status, patient preferences and physician-related factors $(10,11)$. To fully understand the impact of linking the volume-outcome relationship to healthcare policy, we are urgently in need of further work to define access to care and investigate sources of disparities.

The relaxing of the volume requirements for TAVR in the recently revised CMS NCD for TAVR (June 2019) provides a rare opportunity to investigate the impact of adopting the volume-outcome relationship as health policy. Specifically, an assessment of whether the relaxation of the volume requirement has resulted in: (I) a shift in the proportion of minorities undergoing any form of AVR or (II) an increase in the number of patients with severe symptomatic AS undergoing AVR will help quantify the severity of the geographic access problem. It will not, however, address other aspects of access, including insurance status, physician factors and patient preferences.

Lastly, characterizing the extent of access to AVR services is urgently needed as we transition from reliance on volume as a structural measure of quality to risk-adjusted outcomes measures. We must avoid basing accreditation and reimbursement decisions on risk-adjusted quality outcome metrics until we understand their implications for access and disparities.

\section{Conclusions}

The volume-outcome relationship in TAVR and SAVR has been adopted as a de facto quality metric due to its inclusion in the original and revised CMS TAVR NCD. Linking the volume-outcome relationship and healthcare policy has diverted attention from needed investigation into access to and disparities in the provision of transformational AVR technologies. As the measurement of quality in AVR transitions to risk-adjusted outcomes metrics, policy-makers tying accreditation or reimbursement to these metrics will need to carefully balance quality against access and disparities.

\section{Acknowledgments}

Funding: None.

\section{Footnote}

Conflicts of Interest: Grants/Contracts: Abbott Vascular, Boston Scientific, American College of Cardiology, Society of Thoracic Surgeons, National Institutes of Health, Patient Centered Outcomes Research Institute, Food and Drug Administration (NEST); Advisory Board/Consulting: Janssen, Boston Scientific, HeartFlow.

Open Access Statement: This is an Open Access article distributed in accordance with the Creative Commons Attribution-NonCommercial-NoDerivs 4.0 International License (CC BY-NC-ND 4.0), which permits the noncommercial replication and distribution of the article with the strict proviso that no changes or edits are made and the original work is properly cited (including links to both the formal publication through the relevant DOI and the license). See: https://creativecommons.org/licenses/by-nc-nd/4.0/.

\section{References}

1. Tricoci P, Allen JM, Kramer JM, et al. Scientific evidence underlying the ACC/AHA clinical practice guidelines. JAMA 2009;301:831-41.

2. Jollis JG, Peterson ED, DeLong ER, et al. The relation between the volume of coronary angioplasty procedures at hospitals treating Medicare beneficiaries and short-term mortality. N Engl J Med 1994;331:1625-9. 
3. Badhwar V, Vemulapalli S, Mack MA, et al. The Mitral Valve Surgery Volume-Outcome Relationship in the United States. JAMA Cardiol 2020, in press.

4. CMS.gov. Decision Memo for Transcatheter Aortic Valve Replacement (TAVR). 2012. Accessed 12/4, 2018. Available online: https://www.cms.gov/medicare-coveragedatabase/details/nca-decision-memo.aspx?NCAId=257

5. Vemulapalli S, Carroll JD, Mack MJ, et al. Procedural Volume and Outcomes for Transcatheter Aortic-Valve Replacement. N Engl J Med 2019;380:2541-50.

6. Salemi A, Gaudino M, Bakaeen F, et al. Operator Volume to Outcome Relationship in Mitral and Aortic Valve Replacement. J Am Coll Cardiol 2019;74:2821-2.

7. Arnold SV, O'Brien SM, Vemulapalli S, et al. Inclusion of Functional Status Measures in the Risk Adjustment of 30-Day Mortality After Transcatheter Aortic Valve Replacement: A Report From the Society of Thoracic

Cite this article as: Vemulapalli S. Transcatheter aortic valve replacement and surgical aortic valve replacement volumeoutcome relationships: a Pandora's box. Ann Cardiothorac Surg 2020;9(6):493-495. doi: 10.21037/acs-2020-av-16
Surgeons/American College of Cardiology TV'T Registry. JACC Cardiovasc Interv 2018;11:581-9.

8. Alkhouli M, Holmes DR Jr, Carroll JD, et al. Racial Disparities in the Utilization and Outcomes of TAVR: TVT Registry Report. JACC Cardiovasc Interv 2019;12:936-48.

9. Vora AN, Vemulapalli S. Geographic dispersion of TAVR services: Ensuring availability while maintaining quality. Am Heart J 2016;177:160-2.

10. Epstein AM, Weissman JS, Schneider EC, et al. Race and gender disparities in rates of cardiac revascularization: do they reflect appropriate use of procedures or problems in quality of care? Med Care 2003;41:1240-55.

11. Bach PB, Pham HH, Schrag D, et al. Primary care physicians who treat blacks and whites. N Engl J Med 2004;351:575-84. 